\title{
PROSPECTS OF PROBLEM AND PROJECT BASED LEARNING BLEND FOR FOURTH INDUSTRIAL REVOLUTION READY ELECTRONICS ENGINEERING PROGRAMMES IN NIGERIAN UNIVERSITIES
}

\author{
Terungwa Stephen Akor, Muhammad Khair Noordin*, Kamalularifin Subari, Hanifah Jambari, Ahmad \\ Nabil Md Nasir, Mohamad Rasidi Pairan \\ School of Education, Faculty of Social Science and Humanities, Universiti Teknologi Malaysia \\ *mdkhair@utm.my
}

\begin{abstract}
The application of electronics has attained a level where humanity cannot do without electronics however, the study of electronics is not without challenges considering the complex and abstract nature of the course. The obsolete teaching/learning facilities and methods in Nigerian universities has been a major challenge for the past four decades, thus resulting to high level of unemployment and lack of industrial and economic development. Various instructional innovations have been introduced in the teaching and learning processes to cushion the complexity and abstractness of electronics engineering programmes with each of the methods having its limitations. This study seeks to explore how a blend of problem and project-based learning could lead to the acquisition of the desired competencies of electronics engineering based on the needs of the 21 st century industry and the emerging fourth industrial revolution (4IR). To this effect, various problem and project-based learning features like: problem identification and analysis, information gathering, critical thinking, teamwork, effective communication, leadership and continues learning were visited based on the previous research findings. It was concluded that, the features can produce the desired electronics engineering skills that could meet the needs of the 21 st century Industry and the 4IR.
\end{abstract}

Keywords: Problem Based Learning, Project Based Learning, Fourth Industrial Revolution, Electronics Engineering, Nigerian Universities

\section{INTRODUCTION}

We are living in an electronics generation where almost every aspects of our life are tied to electronics. The use and application of electronics has become life's sine-qua-none such that we begin our day, live our day and end our day with electronics. This is because, the usage and application of electronics in all aspects of human activity such as entertainment, information/communication, transportation, education, healthcare services, banking and finance, economy, production and manufacturing cannot be quantified. These benefits, coupled with the complex and abstract nature of electronics (both hardware and software) has placed more demand on the study of the course. For instance, when concepts like the movement of electrons in circuits, diodes, transistors, resistors, capacitors, inductors and recently, Nano-devices are taught, students find the understanding more complex due to the abstract and invisible nature of electrons. All these, couple with the mathematical nature of electronics makes many students shy away from the course.

For decades, researchers have been exploring various teaching and learning methods that could not only make the study of electronics interesting to learners but also enjoyable. It is to this effect that this study seeks to explore the instructional potentials of blending problem-based learning $(\mathrm{PbBL})$ and project-based learning $(\mathrm{PjBL})$ based on the needs of the existing and future industry. The study reviews various research findings in $\mathrm{PbBl}$ and $\mathrm{PjBL}$ to come out with a model that could be used to teach electronics engineering programs in Nigerian Universities and beyond.

\section{PROBLEM BACKGROUND}


The development and sustainability of any society depends of the quality of man power capable of utilizing available resources for the benefit of the citizens and based on the needs of the society. This is indicative that, greatness of any society varies directly with the quality of manpower which depends on the quality of education and the system. The status and position of any nation (developed or developing) in the global ranking depends sorely on the quality of the citizens which in turn, is a product of her quality educational system (Adesogan, 2017). This justifies why Nigeria remains a developing country for almost six decades after her independence. Despite abundant human, material and natural resources, Nigeria lags behind almost all nations like China, Brazil, India, Malaysia and Korea that were on the same page with her less than three decades ago (Saba et al., 2013).The secrete behind the success of these nations is as a result of the restructuring of their educational system with emphasis on Science and Technology Education which provides the requisite skills that are necessary for the utilization of the available resources. This agrees with the findings of Oloyede et al. (2017) that the future of any nation does not only depend on its enormous natural resources possessed but the specialized engineering skills, competence and the ability of its populace to harness and utilize the resources

The poor quality of engineering graduates from Nigerian tertiary institutions (universities and polytechnics) is a clear indication that the nation's educational system particularly, science and technology is in jeopardy (Adesogan, 2017). As a result of the under skilled nature of these graduates, the few surviving industries prefer going for foreign expatriates when the cost of retraining is considered, thus increasing the unemployment level in the country. This, can be blamed on the decaying infrastructural facilities in our higher institutions of learning (Yew \& Goh, 2016). The challenges confronting engineering and technology education in Nigeria could be blamed on various factors. According to United Nations Educational, Scientific and Cultural Organization (UNESCO), the budgeting allocation to the education sector has been in decline over the years with less than $10 \%$ of the national budget as against $26 \%$ recommended by UNESCO (UNESCO, 2015). The consequent effects of this poor funding of education include: Obsolete/worn-out laboratory equipment; difficulties in recruiting quality teachers and inability to retrain the existing ones; poor working environment; inability to cope with the explosive students' population; poor teaching facilities and obsolete teaching and learning methods.

\section{ELECTRONICS ENGINEERING PROGRAMMES (EEPS)}

Electronics engineering is concerned with the utilization of electricity in solving various problems. This can be felt in the continues improvement of the quality of our lives through various equipment in fields of engineering, medicine, communication, transportation, information, entertainment, computing, security, business and education. Electronics engineering is quit a challenging and creative profession responsible for the state-of the-art technologies like security systems, drones, robotics, weather forecast devices, digital cameras, medical devices and control systems (Ushie \& Ogbulezie, 2017). An electronics engineer has the creative and innovative ability to make contribution to the fast advancing global technology, thus offering wide variety of exciting and unlimited career opportunities At the undergraduate level, the programmed is designed to enable graduate to:

i. Apply knowledge of mathematics, science, engineering fundamentals and an engineering specialization to the solution of complex engineering problems

ii. Identify, formulate, research literature and analyse complex engineering problems reaching substantiated conclusions using first principles of mathematics, natural sciences and engineering sciences

iii. Design solutions for complex engineering problems and design system components or processes that meet specified needs with appropriate consideration for public health and safety, cultural, societal and environmental considerations

iv. Use research-based knowledge and research methods including design of experiments, analysis and interpretation of data and synthesis of information to provide valid conclusions

v. Create, select and apply appropriate techniques, resources and modern engineering and IT tools including prediction and modelling to complex engineering activities with an understanding of the limitations

vi. Apply reasoning informed by contextual knowledge to assess societal, health, safety, legal and cultural issues and the consequent responsibilities relevant to professional engineering practice

vii. Understand the impact of professional engineering solutions in societal and environmental contexts and demonstrate knowledge of and need for sustainable development 
viii. Apply ethical principles and commit to professional ethics and responsibilities and norms of engineering practice

ix. Function effectively as an individual, and as a member or leader in diverse teams and in multidisciplinary settings

x. Communicate effectively on complex engineering activities with the engineering community and with society at large, such as being able to comprehend and write effective reports and design documentation, make effective presentations and give and receive clear instructions

xi. Demonstrate knowledge and understanding of engineering and management principles and apply these to one's own work, as a member and leader in a team, to manage projects and in multidisciplinary environments

xii. Recognize the need for and have the preparation and ability to Engage in independent and lifelong learning in the broadest context of technological change (Adesogan, 2017). Graduate of this programmes have vast career opportunities in areas of Telecommunications companies and corporations, Civil Service and Government, Network infrastructure companies, Radio and television broadcasters and developers, Electronic component manufacturers, Electrical power utilities, Research and educational centres (Saba et al., 2013).

\section{METHODS OF TEACHING ENGINEERING IN NIGERIAN UNIVERSITIES}

The conventional method of teaching electronics engineering like any other engineering program in Nigeria is the traditional approach. This particular conventional technique is textbook based instruction and practical, hands on lessons. According to Barau (2015) the textbook based instructions are usually together with sensible lessons in which students are able to develop electric circuits and carry out measurements. These sensible lessons are able to help pupils in developing experience as well as skills when dealing with actual equipment. Nevertheless, sensible lessons have limitations this in common discourage pupils from creating a good conceptual comprehension, for instance, in practical lessons pupils are likely to concentrate on helping their circuits go instead of on attempting to understand the causal relations between results and variables. Barau further stated that, the old learning and teaching techniques are not ideal for the learners. What pupils could find out are not just the expertise but much more helpful abilities, for example lifelong learning abilities, critical thinking abilities, problem solving abilities, self-directed learning, and cooperation/communication skills.

Relatedly, Oloyede et al. (2017) observed that, lecture method, conversation method, simulation and project work remain the most popular teaching methods in Nigerian Universities. The lecture strategy can be generally called "talk chalk method" which consists of the mentor outlining the suggestions by providing examples and sometimes, writes on the chalkboard. The task technique, on the other hand, involves active involvement of the learners in such a manner that a cooperative (group) research of a real-world condition in the class is actually undertaken, under the supervision of the instructor. The drama strategy might additionally be classified as a team technique as it entails a group-oriented approach. Nevertheless, the concerned, reactions, as well as thoughts of the learners in that circumstance, are considered throughout the course of mingling with each other. This might additionally be described as the "Role Play Method". The simulation technique is a far more practical oriented approach to teaching where pupils are actually subjected to tools and devices actually. This particular technique is viewed as probably the most effective in Engineering and Science associated subjects as it hastens and also induces the understanding of learners (Oloyede et al., 2017; Ushie \& Ogbulezie, 2017; Barau, 2015). A lot of learning strategies have been identified as well as connected with certain coaching techniques.

According to Bubou et al. (2015), today's Nigerian University, generally, engineering lecture areas are confronted with a comparable situation as it had been in decades before. The teaching strategy is also the traditional strategy in which a teacher provides lectures by standing in the classroom, dictating notes or even deriving equations from the' old' notebook', recycling examples, assignments, and tasks. This particular approach type according to Ushie and Ogbulezie (2017), does not permit skills acquisition, critical thinking, and ingenuity required in a difficult multidisciplinary program as engineering. Notably, several enhancements have been found adhering to the diffusion of ICT into the teaching, and learning process and this also results in some kind of modification on the task. Nigerian engineering training said to be the same to the British, is nonetheless stricken by societal industrial as well as economic limitations (Bubou et al., 2015). They opined that whilst electronics engineering in 
Nigeria cannot be referred to as substandard; it's nonetheless insufficient to entirely equip graduates to cope with the difficulties of modern day society. Nevertheless, the authors who passed through and continue to be physically active participants of the Nigerian instructional program observe this unproductive didactic lecture technique, old fashioned blackboard or maybe whiteboards, classrooms that are overcrowded, technology afraid faculty, absence of ICT program, and so on, nonetheless characterize universities in Nigeria. Also worthy of note is the disastrous consequences of manufacturing actions occasioned by lecturers which always resulted in long stretches of shutdown of the universities. This in many cases results to shortened semesters, therefore making colleges to crash the courses and even further aggravating the issues of the device (Oloyede et al., 2017).

According to Yasin and Rahman (2011), the task which faces the education environment has constantly been to make sure that the teaching as well as learning process takes place efficiently in a classroom atmosphere. Success in engineering learning comes from revolutionary teaching methods and good educational materials. This calls for one to alter the conventional method of teaching electronic and electrical engineering. In the usual teaching methods, lecturers provide program materials of a classroom where pupils listen, take notes, copy items, execute complete tasks and homework. In instances that are a lot of, lecturers forget to transmit expertise to learners efficiently despite individually getting good specialized information in the subject region. This happens since it's usually difficult for learners to take notes and listen with great comprehension simultaneously (Ushie \& Ogbulezie, 2017). Yew and Goh (2016) confirmed that the traditional usage of lectures is a result of the effective use of faculty time, not due to the fact lectures are actually a great way to teach problem solving abilities. Lectures could be a good way to communicate facts, like in a history class. But probably the most difficult job for science as well as engineering pupils is actually learning a number of methods for fixing issues, not learning facts. In case learners are able to learn from listening to a lecture, next they ought to be in a position to master the very same stuff by reading through a publication, making lectures unessential.

According to Bubou et al. (2015), professional competence in teaching is guided by two major elements which are the knowledge of subject or topic to be taught and the capability to teach it in the way as to bring about learning on the part of the student's. Poor educational technique might partly have contributed to the students' very poor performance in electronic and electrical engineering. For that reason, the instruction methods used by almost all lecturers don't appear to effectively deal with the diverse learning, types, and tastes of the learners (Saba et al., 2013). Many industries criticism that a significant number of graduates creates every year from universities as well as polytechnics lack required job site abilities needed by the business and thereby cause them to become unemployable (Barau, 2015). This might stem from inadequate pedagogical abilities in teaching. For good teaching to take place, competent teachers have to make use of skilled strategies and various means of teaching at their disposal. Although there's an excellent diversity of teaching techniques and methods, there's no one of them that may be viewed as the very best. A meticulously created coaching strategy is able to work wonders in ensuring a successful learning. According to Ibrahim and Halim (2014), the different techniques to the training of specialized trades have been discovered to be the same with the way science subjects are now being taught in the schools of ours. Demonstration technique is often used to teach basic operations in specialized training, this particular strategy will help the professor to clarify the steps involved in an operation or a session while instructing them. By means of this teaching/ learning technique, pupils generally use two or even much more of their learning senses. Bubou et al. (2015) posited that demonstration as well as task method of teaching has been the most typical teaching technique in specialized education. This's very easy to learn with the focus which comes in an exercise programme based on manipulation to fabricate and service treatments with the supplies as well as equipment of business. Olaitan as cited in Oloyede et al. (2017), explained that educational strategies applicable to the training of specialized training courses are actually task, conversation, demonstration excursion or maybe assignments and field trip. He further reported that lecture strategy may be used where needed. These techniques must be utilized efficiently since electronic and electrical engineering programme is created especially to train personnel who will ultimately be helpful on setup or establish their own workshop.

\section{FOURTH INDUSTRIAL REVOLUTION (4IR) NEEDS}


Continues technological revolution has fundamental impact on our way of living, working as well as socialization. The industrial revolutions over the past decade has its implications on both technology and every aspect of life. For instance, the first industrial revolution utilized water and steam power for mechanization and production; the second used electricity for mass production; the third made use of electronics, information and communication technology for automated production; and now, the fourth industrial revolution (4IR) which is building on digital revolution from the third industrial revolution (Deloitte, 2018). The 4IR is an osmosis of the digital, physical and biological spheres. The speed, scope and the systematic impact of 4IR has distinguishes it from the 3rd industrial revolution, considering the emerging breakthroughs (Alinda Alias et al., 2017). The impact of 4IR is already evidenced in technological innovations like artificial intelligence where cars are self-driven, virtual assisted drones, software translate or invest and many more. Engineering and architectural designs now combine additive manufacturing, engineering materials, and synthetic biology to pioneer a symbiosis between microorganisms, human bodies, consumable products as well as housing systems. More the previous revolution, the 4IR has the potentials of raising global economic levels as well as improving the quality of life across the world. With the revolution, the digital accessibility and affordability of products across the globe is done with ease as services like cad ordering, flight booking, products buying, listening to music, and watching movies and more can be remotely carried out (Deloitte, 2018).

The 4IR is however without challenges that are quite different from those of the previous revolution as it has implications for work force like professionals especially in the electronics engineering which is the back bone of the revolution. Unlike the previous revolutions where skilled workers were replaced or complemented by technology, the 4IR will replaces under skilled or low skilled workers and in return, complement workers with higher skills (Deloitte, 2018). This poses a threat to Nigerian engineers and other developing economies as low-skilled routing jobs in manufacturing and production shall be automated. It is estimated that, 66 per cent of developing countries' jobs are at risks (Oloyede et al., 2017). Also worthy of note is the fact that, Advanced economies are not likely to their share their manufacturing and assembling with developing countries on the basis of low labour cost alone. To this effect, developing countries like Nigeria will lose their benefits as well as their potential economic growth by movement of workers to factory jobs.

\section{PROBLEM BASED LEARNING (PBBL) OVERVIEW}

Problem based learning $(\mathrm{PbBL})$ is a pragmatic instructional approach that enhances learning through active engagement of learners in a meaningful problem. According to Yew and Goh (2016), PbBL is an instructional (and curricular) learner-centred approach that empowers learners to conduct research, integrate theory and practice, and apply knowledge and skills to develop a viable solution to a defined problem. Yasin and Rahman (2011) defines PbBL as an instructional method aimed at preparing students for real-world settings. With requiring students to solve problems as the main format of instruction, $\mathrm{PbBL}$ enhances students' learning outcomes by promoting their abilities and skills in applying knowledge, solving problems, practicing higher order thinking, and self-directing and reflecting their own learning. The PbBL approach gives learners the opportunity to identify and analyse a problem, gather resources towards solving the problem, consider various methods in solving the problem, develop proto-type models, and develop a suitable solution to the problem. The underpinning philosophy in PbBL is that, learning is constructive, self-directed, collaborative and contextual Zhou (2012).

The success of PbBL approach is critically determined by the ill-structured problems which could be interdisciplinary and the teacher who acts as guide or instructor to the learning process well as conduct a thorough debriefing during and at the end of the experience (Ibrahim \& Halim, 2014). Various methods are employed in $\mathrm{PbBL}$ with the anticipated skills development such as, critical thinking, complex analysis, real world problems, evaluation, information sourcing, cooperative learning, communication skills, as well as content and intellectual skills for continuous learning (Yasin \& Rahman, 2011). The process engages students as problem solvers through the identification of problem root and the needed conditions for appropriate solution, thus making the process self-directed learning (Latada \& Kassim, 2017). This enables students who work in collaborative groups to identify the 
learning needs in problem solving, engage in self-directed learning, apply their knowledge to the problem, and reflect on previous learning as well as the employed strategies' effectiveness.

\section{Features of PBBL}

Various studies on PbBL proved its effectiveness in knowledge and skills acquisition such as critical thinking, collaborative learning, team work and innovative reasoning. Unlike in the conventional methods of method, $\mathrm{PbBL}$ enables the learners to acquire both cognitive as well as practical skill simultaneously and within a shorter period (Yew \& Goh, 2016). Also, in favour of PbBL is the longterm learning effect as meta-analysis finding showed that, it is more effective when measurement outcomes are measured based on long term retention of knowledge and skill acquisition and application. To ensure the appropriate exploration of $\mathrm{PbBL}$, effectiveness and feasibility, subject level implementation is necessary. To this effect, the integration of subject-centred mini lectures is recommended to enhance the design of a problem. The mini lectures which should not exceed half an hour should be integrated in the tutorial session based on the objectives and contents the particular tutorial session.

The presentation of the problem is in various formats which include but not limited to events, scenarios, prototypes, case-based, audio-visuals, real samples, photographs as well as laboratory sheets. The method is structured by breaking the main problem into sub-problems, followed by integration of the syllabus within the topics (Yew \& Goh, 2016). The sub-problems which cover all topics are mixed-structured with easy and challenging problems (Noordin et al., 2011). To ensure proper schedule of the exercise as well as dependent learning, each sub-problem is developed to last within two weeks period of the solution to the problem. This is done by proposing an artificial problem with same features as the real world with open-ended solutions regardless of the final result.

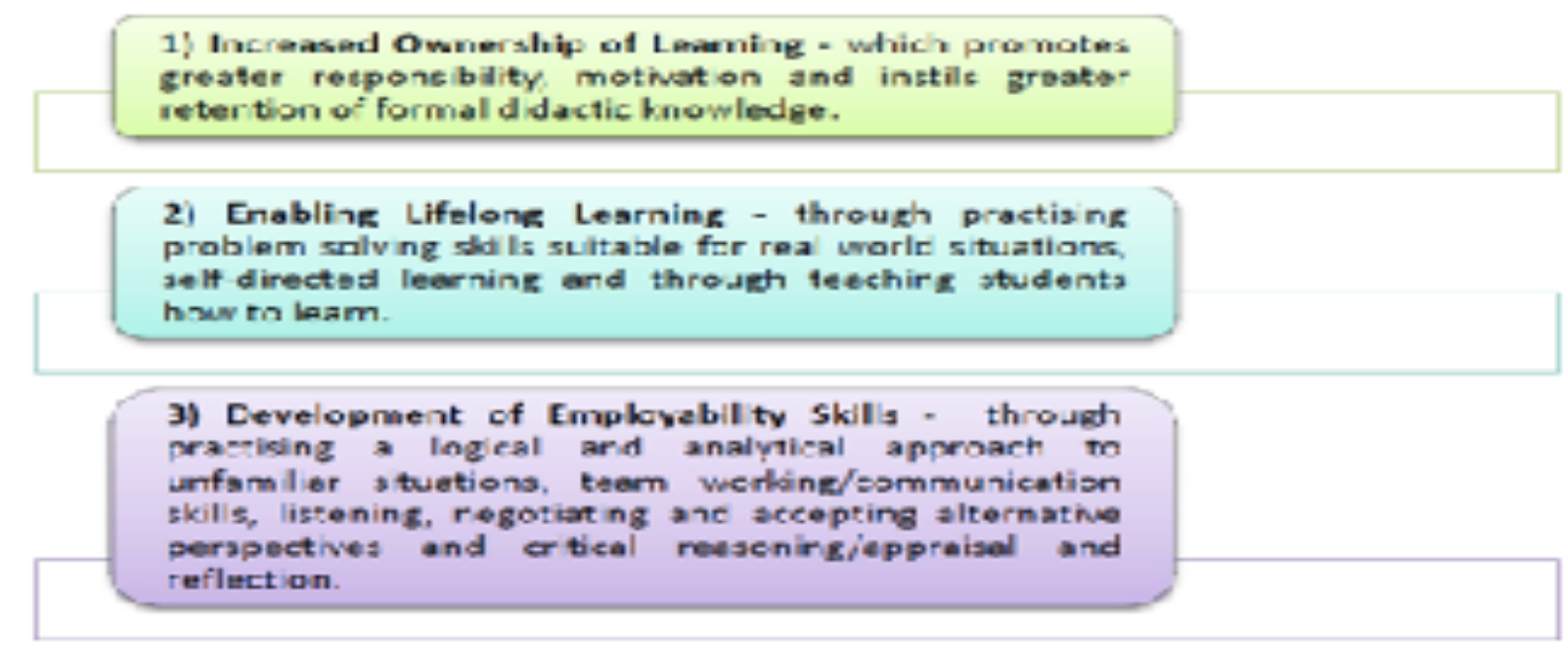

Figure 1. $\mathrm{PbBL}$ features

The facilitator role of teachers varies according to the course and the nature of the existing problem. Across the spectrum, students are free to identify and define their problem in a guided structured project; instead of a rigid procedure, students are guided within limits to proceed with their learning process; the focus of PbBL on structuring the modules' content around the problem scenario instead of specific discipline and topics; $\mathrm{PbBL}$ treats both the learning process and curriculum content in an integral manner; and the novel features of PbBL encourages the blend or integration of academic skills and the societal problems for the development of both transferable skills and specific discipline knowledge (Latada \& Kassim, 2017). The educational benefits of PbBL, according the various findings showed that, it makes adults learning most effective as a result of active collaborative learning process that utilizes contextually relevant materials and resources (Yew \& Goh, 2016). It also builds on the knowledge of novel problem. The key benefits are as shown in Figure 1.

\section{Process of PbBL}


The $\mathrm{PbBL}$ process involves dividing the students into groups of five to six members. In the first group meeting, students begin by defining the problem as well as the learning outcomes, this is followed by group discussion and sessions of mini presentation (Yew \& Goh, 2016). The process of solving the problem provides all groups with similar problems sites and problems are designed with open ended solution, thus, ruling out the issue of plagiarism. Students are encouraged to share their materials within and amongst other groups' members but the solutions to the problems are expected to differ. At the mini presentation, groups are expected to share their problem solutions and are expected to apply different solutions using similar principle and concepts (Noordin et al., 2011).

The facilitators' role in first tutorial meeting is to guide the students through the process of problem solving, to this effect, the problem understanding process begins the session and students identify what they know as well as what is expected and yet to know (Latada \& Kassim, 2017). This process is done by asking students questions that will task and activate their mental ability to utilize the previous knowledge as well as the available resources to solve the problem (Zhou, 2012). The next step involves continues questioning and process monitoring by facilitators. In the last session of problem solving, the facilitators are expected to give immediate feedback to the groups after the mini presentation session and the feedback comments must be based on the provided rubric rating scale. As mentioned earlier, the PbBL process changes the role of teachers to instructors and facilitators who monitor thee groups with hands on guidance, information and support as well as ensuring meaningful relevant discussion. The procedure, according to Keele University introduces students' groups to open ended challenges, scenarios or trigger through the process shown in Figure 2.

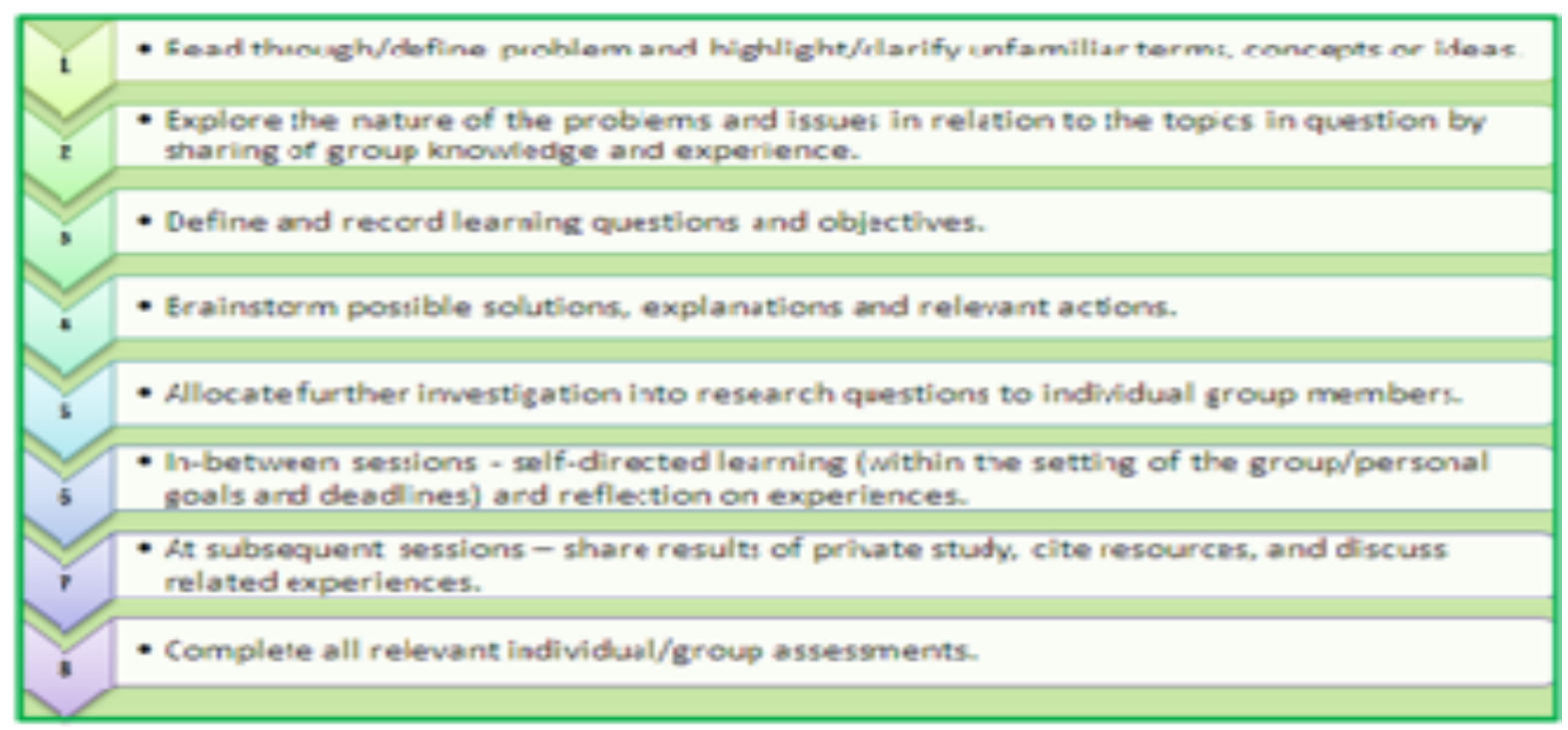

Figure 2. $\mathrm{PbBL}$ process

\section{PROJECT BASED LEARNING (PJBL) OVERVIEW}

Project-Based Learning (PjBL) is an innovative teaching method that has been applied in various educational content settings for some decades. The method utilizes practical concepts applications thereby creating connection between the learned content and the real world (Ibrahim \& Halim, 2014). The created connection enables students to visualize creative opportunities for them to utilize the sourced information in the real world to execute a project. This enhances the students' ability to retain and understand even abstract concepts as a result of the hands-on environment created by PjBL. Project based learning also provides students with multiple opportunities to enhance skills that will be needed in the future. Students learn how to collaborate and bounce ideas off of each other (Noordin et al., 2011). This promotes problem solving and critical thinking skills thus, providing learners with divergent thinking as well as effective and efficient solution. According to Latada and Kassim, (2017), the skills acquired through PjBL based on existing problems are likely the ones that are needed by the industry and the immediate society. This creates opportunities for students to develop their cognitive as well as effective domain necessary for a successful career especially in engineering, science and technology. 


\section{Features of PjBL}

The use of PjBL engages students in solving complex societal problems and students are allowed in most cases to select their problems based on their meaningfulness; students are required utilize various skills like, inquiry, planning, research, critical thinking as well as problem solving skills in executing a project; PjBL requires students to learn and apply knowledge and skills based on specific content in various context in the course of carrying out the project; students are opportune to learn and apply interpersonal skills in a cooperative manner in workplace or community; it develops students' practical skills that could be later utilized in adult and career life as well as time and resources management, personal responsivity, interpersonal skills and learning experience; enhances students critical thinking skills that enables them to link previous knowledge and skills with respect to the existing project; and the process ends with a presentation of a product that demonstrates learning and is assessed based on students' criteria (Yasin \& Rahman, 2011).

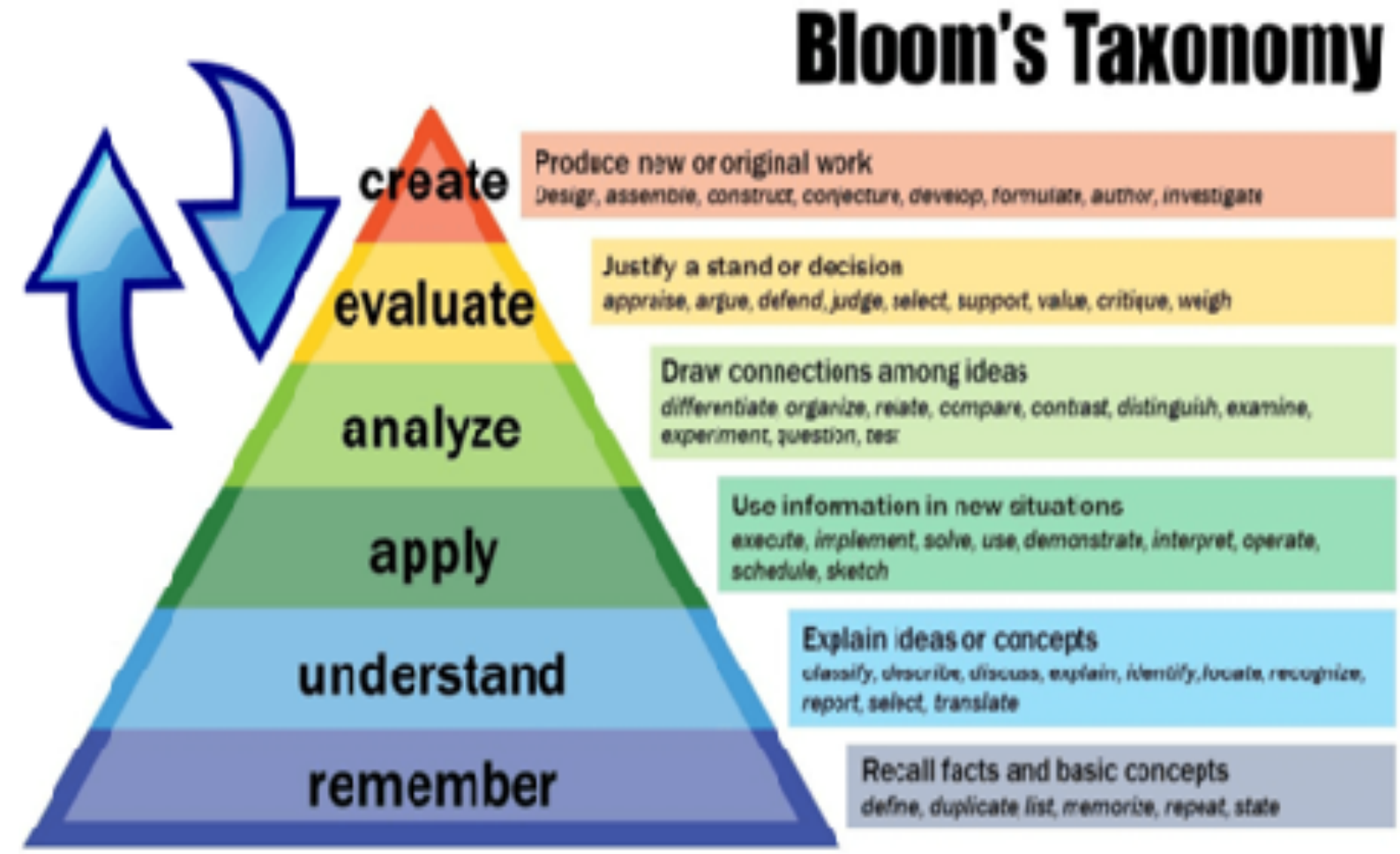

Figure 3. PjBL to Flip Bloom's Taxonomy for Deeper Learning

\section{Process of PjBL}

Project-Based Learning Unit:

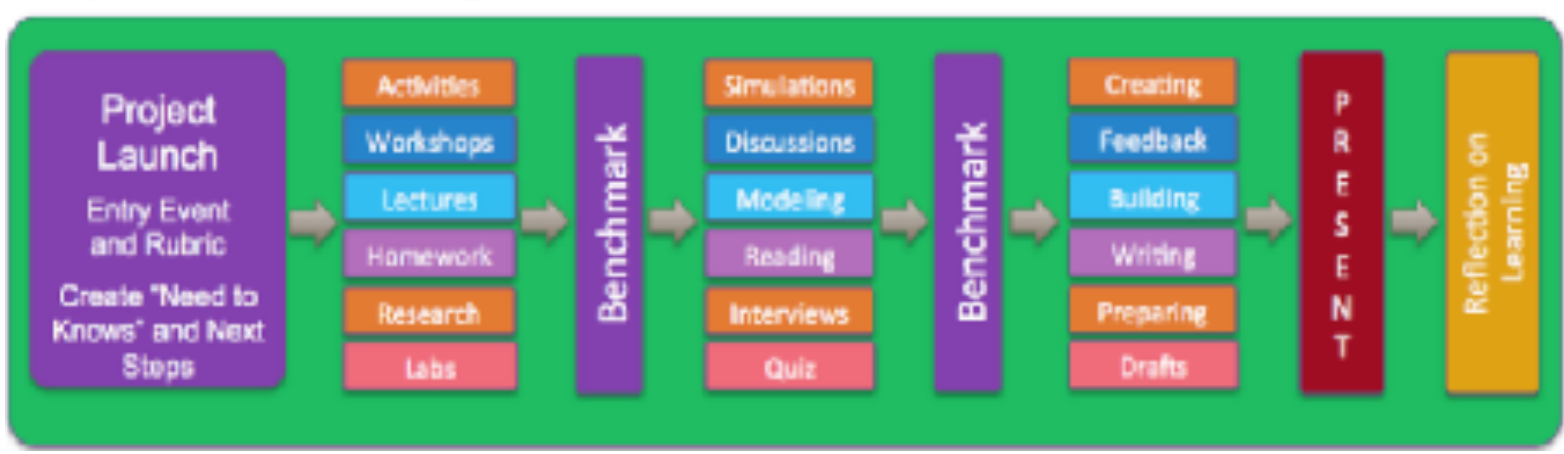

Figure 4. $\mathrm{PjBL}$ process

Before commencing a PjBL process, it advisable to prepare the timeline and the benchmarks for the various stages as well as make adequate provision for all the requirement for the project. This should be followed by creating a collaborative learning environment as well as simulation facilities to take 
care of mistakes from students. The setup should enable students to display their previous knowledge and skill as well as enable them acquire new ones in the process. The process is unveiled as follows:

i. Project Launch: this stage involves the collective brainstorming by students to ascertain their entry level readiness. They review their scope of the project and its rubrics to determine the individual objectives and questions. This enables them to focus on each individual question as well as learn from others who are working on their individual questions.

ii. Team Roles, Initial Research and Project Proposal: at this stage, each team group meet to brainstorm the questions and research needs as well as receive rubric roles and responsibilities. Distinct roles are assigned to each team member with every team having a project manager, writer, presenter, and organizer.

iii. Benchmark check: the team's presenter introduces the project proposal to the group for peer questioning and answering followed by feedback and constructive criticism. The feedback and criticism gives room for corrections and amendments.

iv. Research, Final Products, Guest Perspectives: stage four involves feedback discussion, project research and recommendations as well as tasks' master list. The tasks' list is used to decide the team's final product and additional relevant task to be added to the timeline.

v. Benchmark check: at this point, the presenter of the team introduces the resulting product idea to the group, some initial information is incorporated to determine the appropriateness of the resulting product. This is done by peers' questioning, props and feedbacks as well as sharing of relevant information and resources that are related to the final product.

vi. Bringing it all together: stage six involves decision making on feedbacks, corrections and needed changes. The teams prepare for the presentation by trial running the product and the presentation.

vii. Presentations: the presentation takes variety of formats and are normally spaced out for a period of days. The team is encouraged to invite the public to form the audience as this adds value to the project.

viii. Reflection, Feedback/Recommendations: at this stage, students reflect on the project execution processes, resources used, knowledge and skills acquired as well as how the acquired skills and knowledge could be applied for further projects. The difficulty areas and stages are identified and deliberated upon on how to tackle such in subsequent projects. The process is as summarized in Figure 4.

\section{THE PBPL AND PJBL BLEND}

$\mathrm{PbBL}$ and $\mathrm{PjBL}$ are forms of constructivism, student-centred and group working approaches. These approaches are based on knowledge application principle to real-world problem that makes learning more active and authentic. They actively engage students in projects that are thought-provoking and problem-solving skill, investigation and decision making (Noordin et al., 2011). The constructivist theory, according to UNESCO. (2015), which stated that, "students gain a deeper understanding of material when they actively construct their understanding by engaging in and applying ideas". Despite the similarity of $\mathrm{PbBL}$ and $\mathrm{PjBL}$, differences exist as can be seen in the previous discussions. Whereas, in $\mathrm{PbBL}$ students are challenged to solve an open-ended, ill-structured question, $\mathrm{PjBL}$ is structured to search for a solution to a problem. The product of the project is either a product or an enhancement of performance, thus, making $\mathrm{PbBL}$ a subset of $\mathrm{PjBL}$. Figure 5 shows similarities and differences between PbBL and PjBL. 


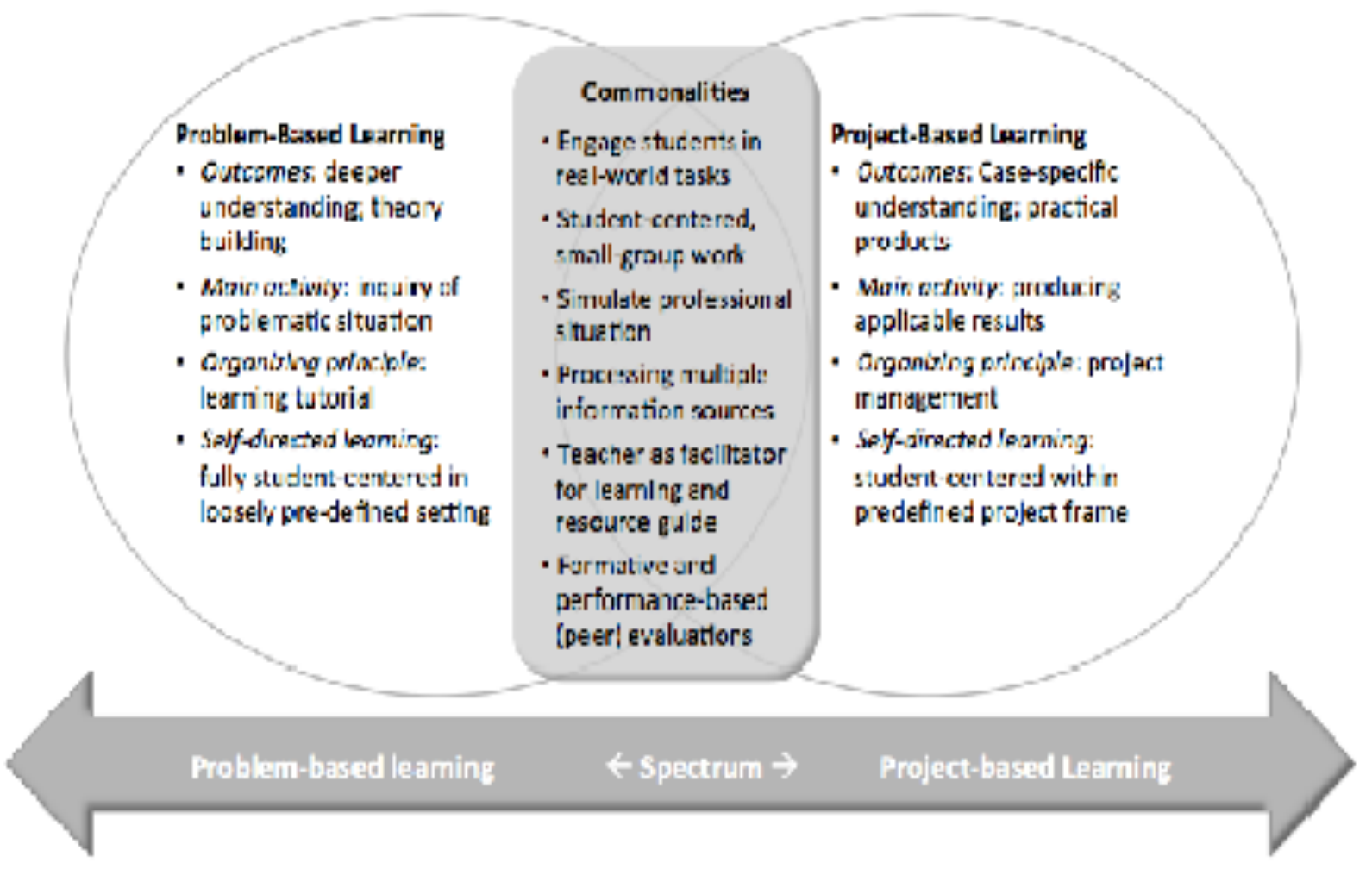

Figure 5. Similarities and differences between PbBL and PjBL (Wiek et al., 2014)

\section{LEARNING IMPLICATIONS OF PBBL AND PJBL BLEND}

Considering the individual instructional merits of $\mathrm{PbBL}$ and $\mathrm{PjBL}$, it is obvious that blending the two approaches can provide the students the opportunity to retain and utilize the knowledge, skills derived from the processes, concepts, principles as well as theoretical models and apply them in solving real societal problems and scenarios. The activities have the benefits of reinforcing existing knowledge as well as provide to the newly learned theories. Also worthy of note is the fact that, the blend lays a foundation for students to tackle difficult concepts as well as develops work place collaboration skills. The teachers' role completely changes to facilitators in an active focused group work where students are free to choose relevant topics that can be applied in solving a problem through a project. According to Wiek et al. (2014), "the shift from teaching to facilitation stimulates a reflective and iterative learning environment". Learning ownership can be increased when teachers hold unto the students directed learning philosophy. The intention of young people to take ownership of ideas, processes, directions and to engage with motivation in their own creative journey provides assurances that manifestations of their 'selves' as individual and unique learners are valued and safe in that personal perspective and what might at times be seen as idiosyncrasies are acceptable and contribute to the general dynamic culture. In this way they feel creative and able to act independently (Zhou, 2012). To this effect, $\mathrm{PbBL}$ and $\mathrm{PjBL}$ teachers are expected to master learners rather than representing authorities in knowledge transmission.

\section{IMPLICATIONS FOR ELECTRONICS ENGINEERING AND 4IR}

Blending $\mathrm{PbBL}$ with $\mathrm{PjBL}$ results to three important, interrelated learning components, namely: problem, project and teamwork. The resulting feature of this blend are students centred, collaborative and self-directed learning, with real world problem solutions as the primary focus. The blend of PbBL and $\mathrm{PjBL}$ has the potentials of playing a complementary role by overlapping in important areas when applied in the teaching of electronics engineering. This helps engineers to adopt problem inquiry as in $\mathrm{PbBL}$ to develop various optional solutions as well as product-orientation as in PjBL. The implication being that, the blend eliminates the risk of endless problem analysis when only PbBL is used as well as jumping to solutions prematurely without sufficient enough problem analysis. In addition, the 
involvement of stakeholders in collaborative process expands the engagement structure of the wider public of PbBL.

The blend also enables students to solve real word problem by applying knowledge through team work not regarding the instructors' timing of the syllabus. It has the potentials of exposing students' technical skills as well as the nom-technical skills such as: cooperation, effective communication, critical thinking, creativity, project planning and management. These skills are commensurate with the engineering skills needs of the 4IR which include complex problem solving, critical thinking, creativity, people management, coordinating with others, emotional intelligence, judgement and decision making, service orientation, negotiation and cognitive flexibility. Creativity which is a core skill in both PbBL and PjBL as well as the 4IR will become a top skill to be demanded by engineers and the influx of new products, technologies and working approach will compare engineers to be more creative to benefit from the changes. With this, only engineers with robotic complementary skills will be found relevant in the industry and world of work.

\section{CONCLUSION}

Electronics engineering is playing a leading role in the 21 st century industry as well as the emerging 4IR as can be seen in all aspects of life, however, the challenges posed by the 4IR are such enormous that any society that fail to braze up is likely to be skimmed out of modernization, civilization and development. This can only be achieved through the right form of education and training using relevant teaching and learning approaches. The instructional prospects of blending PbBL and PjBL for the training of electronics engineers are enormous as can be seen from previous findings in different fields. The blend can motivate learning flexibility as well as self-directed learning of electronics engineers considering its structured approach which integrates research elements and reallife societal problem-solving skills. Further research should focus on assessment methods of blended $\mathrm{PbBL}$ and PjBL.

\section{REFERENCES}

Adesogan, S. O. (2017). Engineering practice in Nigerian university - A microcosm of engineering development and practice in developing countries. 3(6).

Barau, S. (2015). Enhancing teaching and learning of electrical power engineering in the Nigerian tertiary institutions. International Journal of Learning and Teaching, 1(1), 55-58.

Bubou, G. M., Offor, I. T., \& Gumus, S. (2015). An argument for the practice of evidence-based teaching in engineering education for developing countries with focus on Nigerian universities. In QScience Proceedings, $p$ p. 1-6.

Deloitte. (2018). The fourth industrial revolution is here: Are you ready? https:// www.huffingtonpost.com/craig-zamary/the-fourth-industrial-rev_3_b_12423658.html\%0Ahttps:// www.forbes.com/forbes-insights/wp-content/uploa $\bar{d} s / 2018 / 01 /$ DeloitteFourthIndustrialRev_Report_Final-Web.pdf.

Ibrahim, N., \& Halim, S. A. (2014). Generic framework design of project-oriented problem-based learning (POPBL) for software engineering courses. In IEEE 8th Malaysian Software Engineering Conference, pp. 359-364.

Latada, F., \& Kassim, H. (2017). Problem-oriented project-based learning (POPBL): An initiative to encourage soft skills expansion among students at a public. Journal of Global Business and Social Entrepreneurship, 1(3), 75-83.

Noordin, M. K., Nasir, A. N. M., ALI, D. F., \& Nordin, M. S. (2011). Problem-Based Learning (PBL) and Project-Based Learning (PjBL) in engineering education: A comparison. In Proceedings of the IETEC, pp. 1-14.

Oloyede, A. A., Ajimotokan, H. A., \& Faruk, N. (2017). Embracing the future of engineering education in Nigeria: Teaching and learning challenges. Nigerian Journal of Technology, 36(4), 991-1001.

Saba, T. M., Ma 'aji, S. A., \& Tsado, J. (2013). Assessment of pedagogical skills in teaching of electrical and electronics engineering in the universities in Northern Nigeria. Review of Education Institute of Education Journal, University of Nigeria Nsukka, 23(1), 123-136. 
United Nations Educational, Scientific and Cultural Organization (UNESCO). (2015). Trends in government expenditure for public education, 2011-13. http://unesdoc.unesco.org/images/ 0023/002324/232476e.pdf.

Ushie, O. J., \& Ogbulezie, J. C. (2017). Teaching and learning methodologies in engineering education in Nigerian universities. Global Journal of Engineering Research, 15(1), 63-69.

Wiek, A., Xiong, A., Brundiers, K., \& van der Leeuw, S. (2014). Integrating problem- and projectbased learning into sustainability programs. International Journal of Sustainability in Higher Education, 15(4), 431-449.

Yasin, R. M., \& Rahman, S. (2011). Problem oriented project based learning (POPBL) in promoting education for sustainable development. Procedia - Social and Behavioral Sciences, 15, 289-293.

Yew, E. H. J., \& Goh, K. (2016). Problem-based learning: An overview of its process and impact on learning. Health Professions Education, 2(2), 75-79.

Zhou, C. (2012). Integrating creativity training into problem and project-based learning curriculum in engineering education. European Journal of Engineering Education, 37(5), 488-499. 